\title{
Emerging roles of left ventricular assist device therapy as bridge to transplant in an Asian city with scarce heart transplant donor
}

\author{
Ka-Lam Wong ^^, Ka Lai Cally $\mathrm{Ho}^{2}$, Oswald Joseph Lee², Kin Shing Lun ${ }^{3}$, Inderjeet Bhatia ${ }^{2}$, \\ Wai Ying Eva Tam ${ }^{1}$, Yue Yan Katherine Fan ${ }^{1}$, Wing Kuk Timmy Au ${ }^{2}$ \\ ${ }^{1}$ Cardiac Medical Unit, Grantham Hospital, Hong Kong, China; ${ }^{2}$ Department of Cardiothoracic Surgery, Queen Mary Hospital, Hong Kong, China; \\ ${ }^{3}$ Department of Paediatric Cardiology, Queen Mary Hospital, Hong Kong, China \\ Contributions: (I) Conception and design: KL Wong, KLC Ho, OJ Lee, KS Lun, YYK Fan, WKT Au; (II) Administrative support: All authors; (III) \\ Provision of study materials or patients: All authors; (IV) Collection and assembly of data: All authors; (V) Data analysis and interpretation: All \\ authors; (VI) Manuscript writing: All authors; (VII) Final approval of manuscript: All authors. \\ Correspondence to: Ka-Lam Wong, MBBS. Office of Cardiac Medical Unit, 5/F Kwok Tak Seng Heart Centre, Grantham Hospital, 125 Wong Chuk \\ Hang Road, Aberdeen, Hong Kong, China. Email: micangus@gmail.com.
}

Background: Left ventricular assist device (LVAD) has been increasingly used in patients with advanced heart failure. This study aimed to assess the impact of implementation of LVAD therapy on heart transplantation (HTx) service in Hong Kong (HK).

Methods: LVAD program was started in 2010 in HK and patients who had been put on HTx waiting list since the start of HTx program in HK from 1992 to 2020 were included for analysis. Survival on HTx waiting list between pre-LVAD era 1992-2009 and post-LVAD era 2010-2020 were analyzed by KaplanMeier method and compared by log-rank test. Multivariate analysis by time-dependent Cox-proportional hazard model was used to identify independent predictors of HTx waiting list mortality.

Results: A total of 478 heart transplant listing episodes involving 457 patients were included for analysis. There were 232 heart transplantations (HTxs), including one re-transplantation, during the study period. There were 110 patients who received LVAD as bridge to transplantation (BTT) and 30 of them had undergone subsequent HTx. The 1-, 2- and 3-year survival on waiting list were $82.3 \%, 61.7 \%$ and $43.0 \%$ respectively in the pre-LVAD era $(\mathrm{n}=178)$, while the 1-, 2 - and 3-year survival were significantly improved at $85.7 \%, 81.8 \%$ and $78 \%$ respectively in the post-LVAD era $(\mathrm{n}=300),(\mathrm{P}=0.003)$. Time-dependent multivariate analysis revealed that LVAD support was independently associated with significant reduction of waiting list mortality [odds ratio (OR): $0.21 ; 95 \%$ confidence interval (CI): $0.10-0.44, \mathrm{P}<0.001$ ]. There was no significant difference when comparing survival after LVAD as BTT and survival after HTx up to 8 years (76.1\% vs. $72 \%$ at 8 years respectively, $\mathrm{P}=0.732$ ).

Conclusions: Waiting list survival improved in the post-LVAD era driven by the implementation of LVAD service. Long-term survival for LVAD recipients as BTT were comparable to heart transplant recipients in HK.

Keywords: Left ventricular assist device (LVAD); heart transplantation (HTx); heart failure

Submitted Feb 20, 2021. Accepted for publication Sep 16, 2021.

doi: $10.21037 /$ jtd-21-298

View this article at: https://dx.doi.org/10.21037/jtd-21-298

\footnotetext{
$\wedge$ ORCID: 0000-0002-5328-0320.
} 


\section{Introduction}

Despite the advancement in the heart failure treatment, the prognosis of patients with advanced stage $\mathrm{D}$ heart failure is extremely poor with the 5 -year survival rate of 20 percent and the treatment options remain limited (1-3). Heart transplantation (HTx) has been the standard therapy for suitable patients with advanced heart failure but limited donor availability remains the Achilles' heel for this therapy and mortality on transplant waiting list remains high (4-6). The number of heart transplants in Hong Kong (HK) remained low with only 10 heart transplants performed in a 7.5-million population in 2020. The use of pulsatile left ventricular assist device (LVAD) was first approved as bridge to transplantation (BTT) in mid-1990s and as destination therapy (DT) in $2003(7,8)$. Subsequently, the improvement in LVAD pump design has led to significant improvement in clinical outcomes which resulted in more widespread use of LVAD for advanced heart failure (9-12) with the annual LVAD implantation number increased from less than 500 before 2007 to more than 2,600 in 2018 in the Interagency Registry for Mechanically Assisted Circulatory Support (INTERMACS) registry $(13,14)$. However, the impact of the implementation of LVAD service in the setting of scarce heart transplant donor in an Asian city remained unclear. This study aimed to evaluate the impact of the implementation of LVAD therapy on the HTx service in HK.

We present the following article in accordance with the STROBE reporting checklist (available at https://dx.doi. org/10.21037/jtd-21-298).

\section{Methods}

\section{Patient population}

This was a retrospective cohort study. LVAD service has been implemented in HK since 2010. All consecutive HTx listing episodes since the start of the only heart transplant program in HK in 1992 until 31st December 2020 were included for analysis and all heart transplant listing episodes were followed till events on waiting list, including HTx, death, or delisting, or until 30th June 2021 whichever occurred earlier.

\section{Data attributes}

Patient characteristics including gender, age on heart transplant waiting list, blood group, diagnosis as well as history of smoking, alcohol, diabetes mellitus, hypertension, hyperlipidaemia, transient ischemic attack (TIA), cerebral vascular accident, peripheral vascular disease, chronic kidney disease (CKD) with estimated glomerular filtration rate less than $60 \mathrm{~mL} / \mathrm{min} / 1.73 \mathrm{~m}^{2}$, atrial fibrillation, atrial flutter, sustained ventricular arrhythmia, implantable cardioverter defibrillator (ICD), cardiac resynchronization therapy (CRT), depression, asthma, chronic obstructive pulmonary disease (COPD), tuberculosis, overweight defined as body mass index more than $25 \mathrm{~kg} / \mathrm{m}^{2}$ (15), obstructive sleep apnoea, thyroid disease, hepatitis B carrier status, cirrhosis, deep vein thrombosis (DVT), pulmonary embolism (PE) and malignancy were retrieved. Status at the time of the heart transplant workup and listing including cardiogenic shock, use of intravenous inotropic and/or vasopressor support, use of intra-aortic balloon pump (IABP), use of veno-arterial extra-corporeal membrane oxygenation (VA-ECMO), use of intravascular microaxial LVAD (Impella, Abiomed, Danvers, MA, USA), the need for invasive mechanical ventilation (MV), and the need for temporary renal replacement therapy (RRT) were also retrieved. Data on left ventricular end-diastolic diameter (LVEDD) and left ventricular ejection fraction (LVEF) on echocardiographic assessment; cardiac output, cardiac index, pulmonary capillary wedge pressure (PCWP), right atrial pressure (RAP) and pulmonary vascular resistance (PVR) by right heart catheterization; as well as peak oxygen consumption on cardiopulmonary exercise test $\left(\mathrm{VO}_{2} \max \right)$ were retrieved by reviewing electronic and paper medical records. Time from heart transplant listing to LVAD support were recorded with patients who had LVAD implantation prior the heart transplant listing regarded as having LVAD support at the time of heart transplant listing.

\section{Statistical analysis}

Continuous variables were expressed as mean \pm standard deviation of the mean (mean $\pm \mathrm{SD}$ ). Categorical data were expressed as numbers and percentages. Missing values were tackled by multiple imputation with five imputations used for final pooled analysis. Continuous variables were compared by student's $t$-test or ANOVA as appropriate. Chi Square test was used to determine the differences between categorical variables. Survival on HTx waiting list between pre-LVAD era 1992-2009 and post-LVAD era 2010-2020 were analyzed by Kaplan-Meier method and compared by log-rank test. The fulfillment of proportional hazards assumption was confirmed by testing simple product of the time variable and the covariate as well as the covariate in 


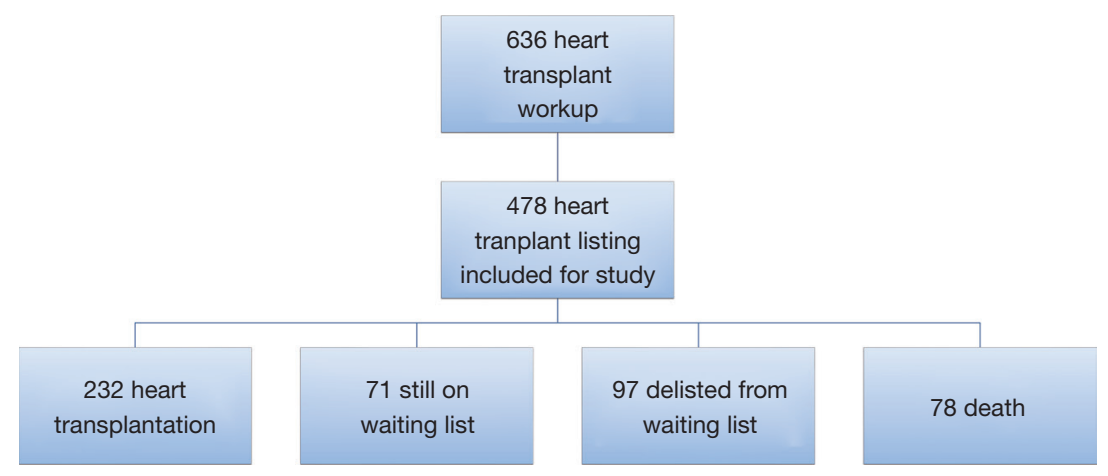

Figure 1 Flow diagram illustrating total number of heart transplant workup and listing episodes during the study period of 1992-2020 and the respective outcomes by 30th June 2021. HTx, heart transplantation.

Cox-proportional hazard model with the result of $\mathrm{P}$ value of the product of the time variable and the covariate $>0.05$. Time-dependent Cox-proportional hazard model was used and factors with $\mathrm{P}$ value $\leq 0.1$ on univariate analysis were accepted for subsequent multivariate analysis to identify independent predictors of waiting list mortality. Time from HTx listing to LVAD support was analyzed as a timedependent variable because not all patients received LVAD support at the time of HTx listing but some received LVAD support later when their condition deteriorated on the HTx waiting list. All tests were two sided, and a $\mathrm{P}$ value $<0.05$ was considered statistically significant. Statistical analyses were performed in SPSS for Windows version 28 (SPSS Inc., Chicago, IL, USA).

\section{Ethical statement}

The study was conducted in accordance with the Declaration of Helsinki (as revised in 2013). The study was approved by the institutional ethics review board (IRB/ REC No. UW 20-388) and individual consent for this retrospective analysis was waived.

\section{Results}

During the study period, there were 636 consecutive heart transplant workup episodes and all the subsequent consecutive 478 HTx listing events $(73.8 \%$ male, mean age 43.9 years old) involving 457 patients during the study period were included for analysis (Figure 1). Nineteen patients were listed twice, and one patient was listed three times on the heart transplant waiting list. Since the start of our LVAD program in 2010, there were a total of
125 patients received LVAD therapy among which there were 110 patients received LVAD as BTT $(85.5 \%$ male, mean age 47.7 years old) while the remaining 15 were either as DT or as bridge to candidacy by the end of the study period. Among the 110 patients with LVAD as BTT, 23, 38 and 49 patients received HeartWare, HeartMate II and HeartMate 3 devices, respectively. Among the whole 478 cohort, there were 167 (34.9\%) dilated cardiomyopathy, $104(21.8 \%)$ ischemic cardiomyopathy, 62 (13.0\%) valvular heart disease, 40 (8.4\%) congenital heart disease, 28 (5.9\%) hypertrophic cardiomyopathy, 26 (5.4\%) myocarditis, 14 (2.9\%) restrictive cardiomyopathy, 13 (2.7\%) arrhythmogenic right ventricular dysplasia or other right ventricular failure, as well as $24(5.0 \%)$ other diagnosis which included familial cardiomyopathy, peripartum cardiomyopathy, chemotherapy related cardiomyopathy, alcoholic cardiomyopathy, cardiac allograft vasculopathy and cardiac allograft dysfunction. Overall, there were $6.6 \%$ of the data missing upon data retrieval for patient characteristics and patient characteristics before and after multiple imputation were summarized in Table S1. Background characteristics of the whole study cohort as well as before (1992-2009) and after the LVAD era (2010-2020) were summarized in Table 1. Patients in post-LVAD era were significantly older, with higher proportion of ischemic cardiomyopathy, having shorter duration of heart failure from initial presentation and having more comorbidities including diabetes mellitus, hypertension, hyperlipidaemia, overweight, atrial fibrillation, ventricular arrhythmias as well as higher rate of use of ICD and CRT when compared to those in pre-LVAD era (Table 1). Patient profiles were significantly sicker in the post-LVAD era with higher proportion of cardiogenic shock, use of inotropes, IABP, 
Table 1 Baseline characteristics of patients at the time of listing for heart transplant waiting list before (year 1992-2009) and after LVAD era (year 2010-2020) after multiple imputation

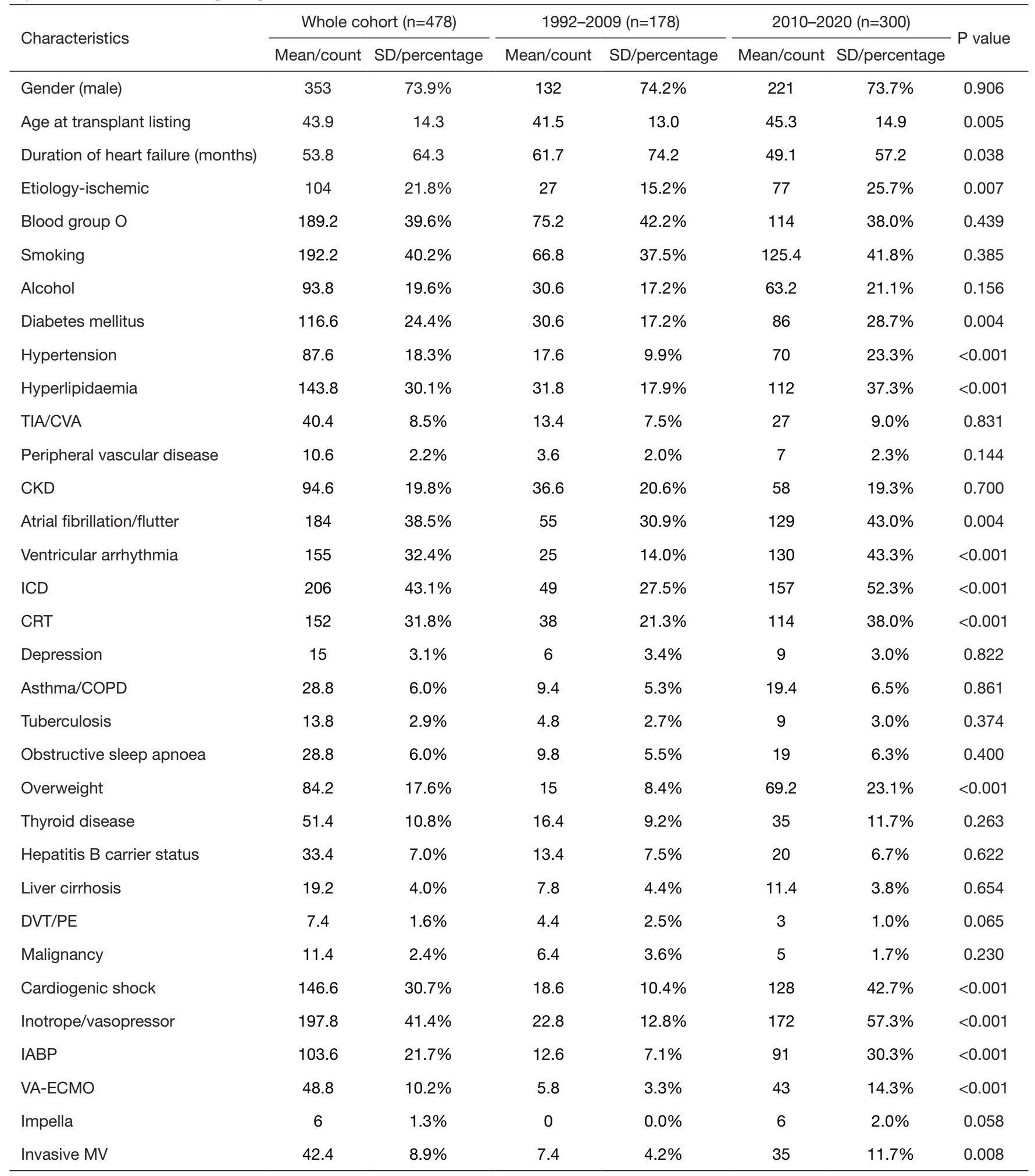

Table 1 (continued) 
Table 1 (continued)

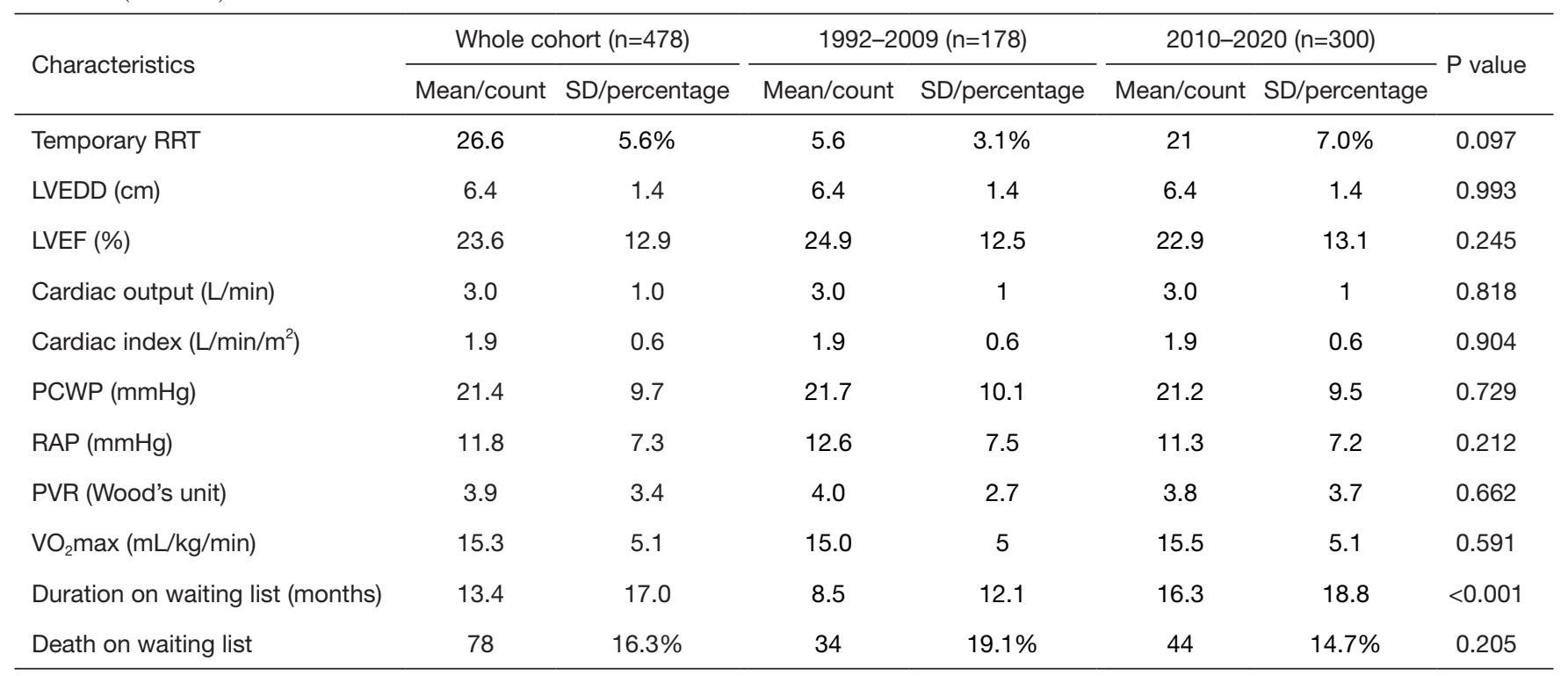

Overweight, body mass index $>25 \mathrm{~kg} / \mathrm{m}^{2}$; Impella, intravascular microaxial LVAD; $\mathrm{VO}_{2}$ max, peak oxygen consumption on cardiopulmonary exercise test. LVAD, left ventricular assist device; SD, standard deviation; TIA, transient ischemic attack; CVA, cerebral vascular event; CKD, chronic kidney disease with estimated glomerular filtration rate less than $60 \mathrm{~mL} / \mathrm{min} / 1.73 \mathrm{~m}^{2}$; ICD, implantable cardioverter defibrillator; CRT, cardiac resynchronization therapy; COPD, chronic obstructive pulmonary disease; DVT, deep vein thrombosis; PE, pulmonary embolism; IABP, intra-aortic balloon pump; VA-ECMO, veno-arterial extra-corporeal membrane oxygenation; MV, mechanical ventilation; RRT, renal replacement therapy; LVEDD, left ventricular end-diastolic diameter; LVEF, left ventricular ejection fraction; PCWP, pulmonary capillary wedge pressure; RAP, right atrial pressure; PVR, pulmonary vascular resistance.

VA-ECMO as well as MV when compared to those in preLVAD era (Table 1). Differences in patient characteristics between patients with LVAD as BTT and patients without LVAD were summarized in Table 2. Patients who received LVAD as BTT were more male predominant, older, with higher proportion of ischemic cardiomyopathy, with higher proportion of smoking habit and alcohol consumption, with more comorbidities including hypertension, hyperlipidaemia, overweight, CKD, ventricular arrhythmia, with higher rate of use of ICD, with higher LVEDD and lower LVEF on echocardiogram assessment, as well as lower mean RAP when compared to those without LVAD (Table 2). More than ninety percent of patients with LVAD as BTT were in INTERMACS profile $1-3$ at the time of LVAD implantation and $21.8 \%$ of the patients required ECMO support as bridge to bridge before LVAD implantation. The mean time from heart transplant listing to LVAD support were 2.3 months (ranged from 0 to 43 months) (Table 2). There was no loss to follow-up in the entire study cohort as all heart transplant listing events were closely followed until definitive events occurred on the waiting list. At the end of the follow-up period, there were 232 HTxs, including one re-transplantation, performed $(70.3 \%$ male, mean age 44.7 years old), 97 delisting episodes, 78 death and 71 patients still active on the heart transplant waiting list (Figure 1).

The number of active patients on the heart transplant waiting list at the end of each year were on average less than 10 in 1992-1999, less than 15 in 2000-2009 and progressively increased to 78 at the end of 2020 (Figure 2). On the contrary, the average number of heart transplants performed in the past 10 years from 2011 to 2020 was about 12 per year and the number remained quite static (Figure 2). Total numbers of heart transplant listing events were 52 in 1992-1999, 126 in 2000-2009 and 300 in 2010-2020.

The overall time on the waiting list till any events including death, HTx and delisting was $13.4 \pm 17.0$ months. Mean time on the waiting list was 9.6 months in $1992-$ 1999, 8.0 months in 2000-2009 and 16.3 months in 2010-2020 $(\mathrm{P}<0.001)$. Mean time on the heart transplant waiting list was significantly longer in the post-LVAD era compared to pre-LVAD era (16.3 vs. 8.5 months, $\mathrm{P}<0.001)$. 
Table 2 Characteristics of patients with and without LVAD

\begin{tabular}{|c|c|c|c|c|c|}
\hline Characteristics & \multicolumn{2}{|c|}{ With LVAD $(n=110)$} & \multicolumn{2}{|c|}{ Without LVAD ( $\mathrm{n}=368)$} & $P$ value \\
\hline \multicolumn{6}{|c|}{ Baseline characteristics at listing for heart transplant waiting list } \\
\hline Gender (male) & 94 & $85.5 \%$ & 259 & $70.4 \%$ & 0.002 \\
\hline Age at transplant listing & 47.7 & 14.1 & 42.8 & 14.2 & 0.002 \\
\hline Etiology-ischemic & 40 & $36.4 \%$ & 64 & $17.4 \%$ & $<0.001$ \\
\hline Blood group $\mathrm{O}$ & 41 & $37.3 \%$ & 148.2 & $40.3 \%$ & 0.615 \\
\hline Smoking & 55.4 & $50.4 \%$ & 136.8 & $37.2 \%$ & 0.017 \\
\hline Alcohol & 33 & $30.0 \%$ & 60.8 & $16.5 \%$ & 0.001 \\
\hline Hyperlipidaemia & 46 & $41.8 \%$ & 97.8 & $26.6 \%$ & 0.003 \\
\hline TIA/CVA & 10 & $9.1 \%$ & 30.4 & $8.3 \%$ & 0.898 \\
\hline Peripheral vascular disease & 4 & $3.6 \%$ & 6.6 & $1.8 \%$ & 0.067 \\
\hline CKD & 30 & $27.3 \%$ & 64.6 & $17.6 \%$ & 0.027 \\
\hline Atrial fibrillation/flutter & 45 & $40.9 \%$ & 139 & $37.8 \%$ & 0.485 \\
\hline Ventricular arrhythmia & 54 & $49.1 \%$ & 101 & $27.4 \%$ & $<0.001$ \\
\hline ICD & 60 & $54.5 \%$ & 146 & $39.7 \%$ & 0.006 \\
\hline CRT & 38 & $34.5 \%$ & 114 & $31.0 \%$ & 0.481 \\
\hline Thyroid disease & 8 & $7.3 \%$ & 43.4 & $11.8 \%$ & 0.213 \\
\hline Hepatitis B carrier status & 10 & $9.1 \%$ & 23.4 & $6.4 \%$ & 0.358 \\
\hline Liver cirrhosis & 2 & $1.8 \%$ & 17.2 & $4.7 \%$ & 0.187 \\
\hline DVT/PE & 1 & $0.9 \%$ & 6.4 & $1.7 \%$ & 0.392 \\
\hline Malignancy & 1 & $0.9 \%$ & 10.4 & $2.8 \%$ & 0.267 \\
\hline Cardiogenic shock & 71 & $64.5 \%$ & 75.6 & $20.5 \%$ & $<0.001$ \\
\hline Inotrope/vasopressor & 88 & $80 \%$ & 106.8 & $29.0 \%$ & $<0.001$ \\
\hline IABP & 49 & $44.5 \%$ & 54.6 & $14.8 \%$ & $<0.001$ \\
\hline VA-ECMO & 22 & $20 \%$ & 26.8 & $7.3 \%$ & $<0.001$ \\
\hline Impella & 6 & $5.5 \%$ & 0 & $0 \%$ & $<0.001$ \\
\hline Invasive MV & 19 & $17.3 \%$ & 23.4 & $6.4 \%$ & 0.001 \\
\hline
\end{tabular}

Table 2 (continued) 
Table 2 (continued)

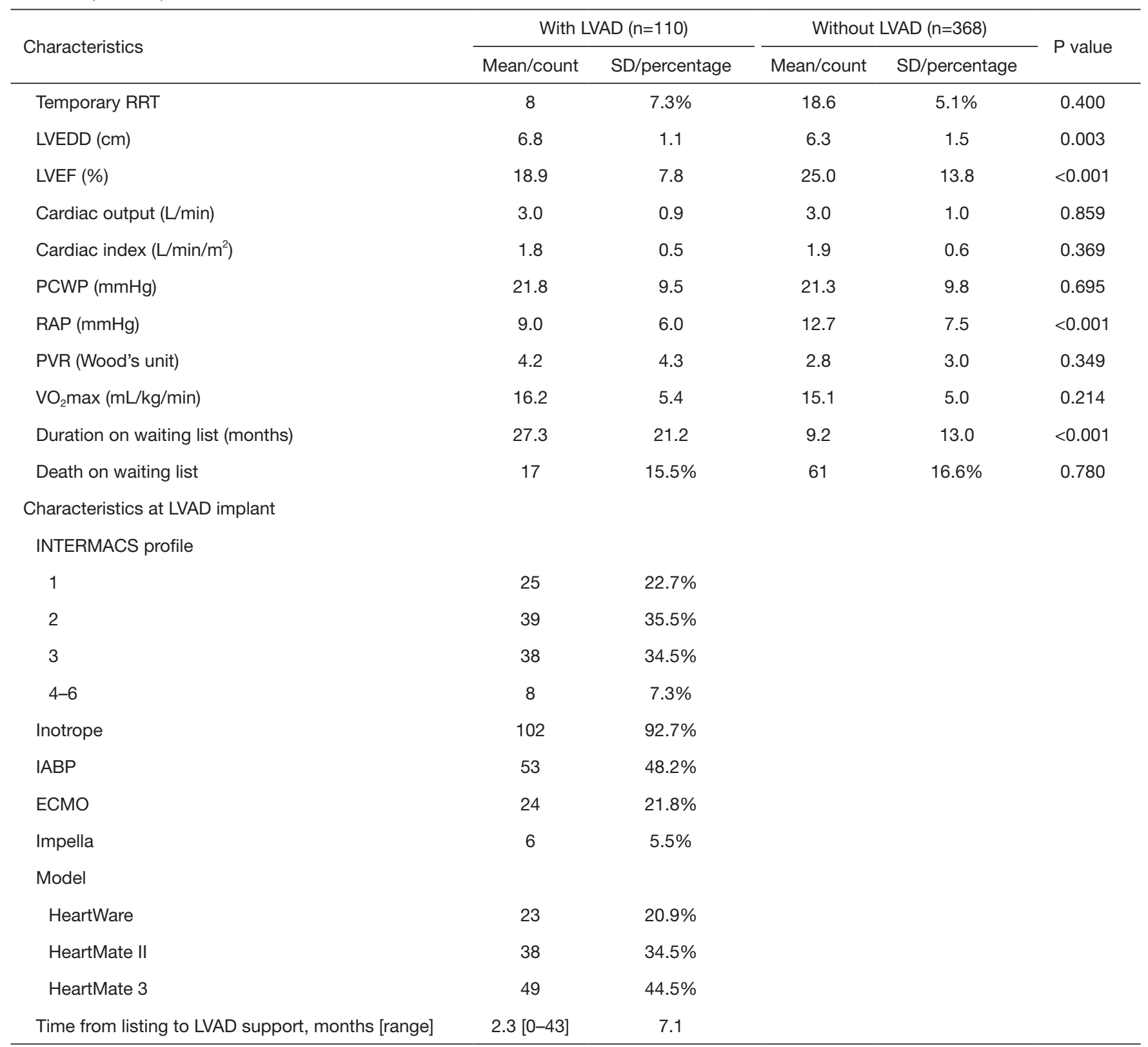

Overweight, body mass index $>25 \mathrm{~kg} / \mathrm{m}^{2}$; Impella, intravascular microaxial LVAD; $\mathrm{VO}_{2}$ max, peak oxygen consumption on cardiopulmonary exercise test. LVAD, left ventricular assist device; SD, standard deviation; TIA, transient ischemic attack; CVA, cerebral vascular event; $\mathrm{CKD}$, chronic kidney disease with estimated glomerular filtration rate less than $60 \mathrm{~mL} / \mathrm{min} / 1.73 \mathrm{~m}^{2}$; COPD, chronic obstructive pulmonary disease; DVT, deep vein thrombosis; PE, pulmonary embolism; IABP, intra-aortic balloon pump; VA-ECMO, veno-arterial extra-corporeal membrane oxygenation; MV, mechanical ventilation; RRT, renal replacement therapy; LVEDD, left ventricular end-diastolic diameter; LVEF, left ventricular ejection fraction; PCWP, pulmonary capillary wedge pressure; RAP, right atrial pressure; PVR, pulmonary vascular resistance; INTERMACS, Interagency Registry for Mechanically Assisted Circulatory Support. 


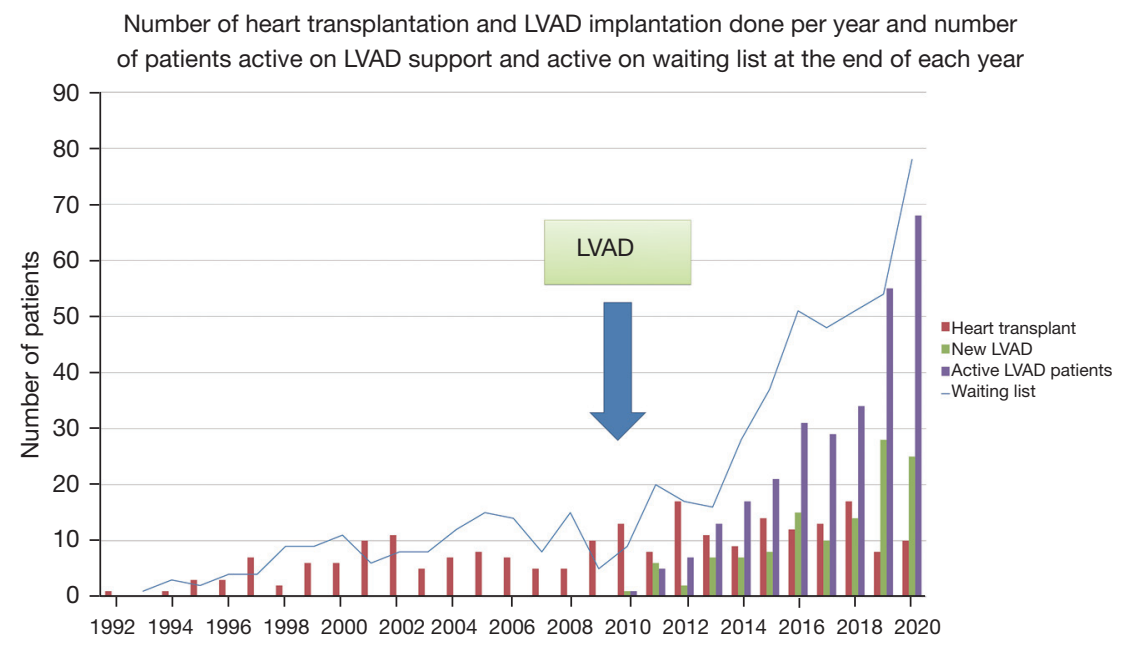

Figure 2 Showed the number of HTx and LVAD implantation performed in each year and number of patients active on LVAD support and active on heart transplant waiting list at the end of each year since the start of heart transplant program in 1992 with the implementation of LVAD program in 2010 marked by blue arrow. LVAD, left ventricular assist device; HTx, heart transplantation.

The difference is mainly contributed by the significantly longer time on the waiting list with LVAD compared to those without LVAD (27.3 vs. 9.2 months, $\mathrm{P}<0.001)$. For successful heart transplant recipients, average waiting time was $9.5 \pm 14.7$ months. Mean time to successful HTx were 5.5, 5.9 and 12.3 months in 1992-1999, 2000-2009 and 2010-2020 respectively $(\mathrm{P}=0.004)$. Mean waiting time to successful HTx was significantly longer in the post-LVAD era compared to the pre-LVAD era (12.3 vs. 5.8 months respectively, $\mathrm{P}=0.001)$. The difference is mainly contributed by the significantly longer waiting time to successful HTx for those with prior LVAD support compared to those without (32.9 vs. 6.0 months respectively, $\mathrm{P}<0.001)$.

The 1-, 2- and 3-year survival rates on waiting list were $82.3 \%, 61.7 \%$ and $43.0 \%$ respectively in the pre-LVAD era $(\mathrm{n}=178)$ while the 1 -, 2 - and 3 -year survival rates were significantly better at $85.7 \%, 81.8 \%$ and $78 \%$ respectively in the post-LVAD era $(\mathrm{n}=300),(\mathrm{P}=0.003)$ (Figure $3 A)$. The survival rate in the post-LVAD era was still significantly better when compared to the two eras 1992-1999 and 2000-2009 ( $\mathrm{P}=0.009)$ (Figure 3B). The use of LVAD support as BTT on HTx waiting list was associated with significantly better survival of $84.8 \%$ vs. $57.0 \%$ at 3-year when compared to those on HTx waiting list without LVAD support $(\mathrm{P}=0.002)$ (Figure 3C).

When assessing the factors associated with HTx waiting list mortality, age at transplant listing, LVEDD, ICD, cardiogenic shock at the time of heart transplant workup and listing, use of VA-ECMO at the time of heart transplant workup and listing, use of Impella at the time of heart transplant workup and listing, the need for invasive $M V$ at the time of heart transplant workup and listing, the need for temporary RRT at the time of heart transplant workup and listing, as well as LVAD support by time-dependent analysis were associated with HTx waiting list mortality on univariate analysis (Table 3). On time-dependent multivariate analysis, LVAD support was independently associated with significant reduction in $\mathrm{HTx}$ waiting list mortality [odds ratio (OR): $0.21 ; 95 \%$ confidence interval (CI): $0.10-0.44, \mathrm{P}<0.001]$ while cardiogenic shock, use of Impella and the need for invasive $M V$ also remained independently associated with waitlist mortality $(\mathrm{P}<0.05)$ (Table 3).

Overall post heart transplant survival rates were $86.6 \%$ and $68.8 \%$ at 1 - and 10 -year respectively with median survival of 18.5 years (Figure $4 A$ ). The post heart transplant survival remained static in different eras (Figure $4 B$ ). There was no significant difference in the post-transplant survival between recipients with and without prior durable LVAD (Figure 4C). Overall survival rates after LVAD implantation for BTT were $86.1 \%, 81.7 \%$ and $76.1 \%$ at 1 -, 2 - and 4 -year respectively. There was no significant difference in survival after LVAD for BTT and after HTx $(76.1 \%$ vs. $72 \%$ at 8 years respectively, $\mathrm{P}=0.732$ ) (Figure $4 D$ ). 

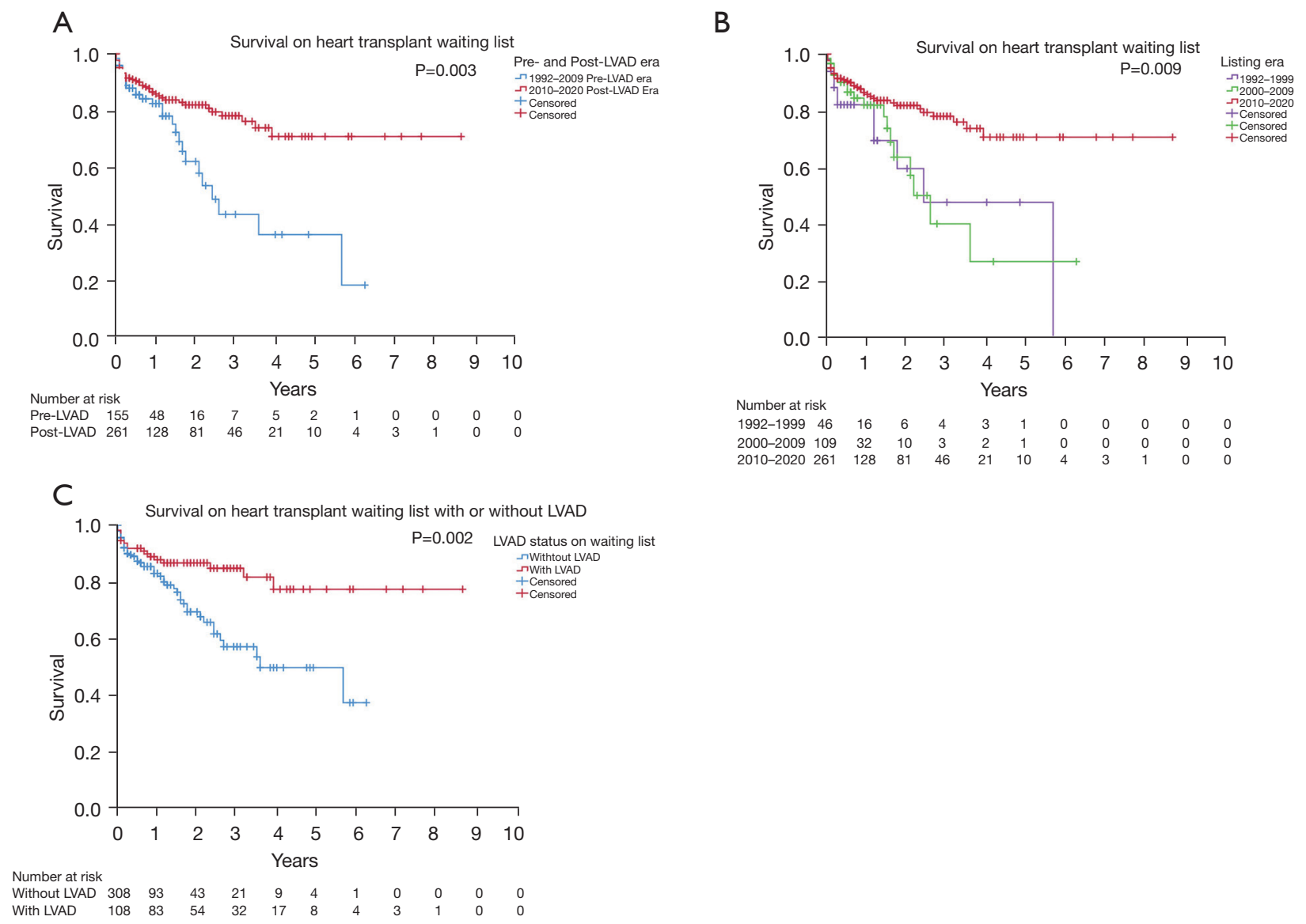

Figure 3 Demonstrated comparisons of survival on heart transplant waiting list among different eras as well as with and without LVAD support. (A) Demonstrated significant better survival in patients on heart transplant waiting list in post-LVAD era 2010-2020 when compared to pre-LVAD era 1992-2009 ( $\mathrm{P}=0.003$ ); (B) demonstrated similar waiting list survival in the era 1992-1999 and 2000-2009 as well as better waiting list survival in post-LVAD era 2010-2020 ( $\mathrm{P}=0.009)$; and $(\mathrm{C})$ demonstrated patients supported on LVAD on heart transplant waiting list was associated with significant better survival when compared to those without $\mathrm{LVAD}(\mathrm{P}=0.002)$. LVAD, left ventricular assist device.

\section{Discussion}

Since the establishment of the heart transplant program in 1992, heart transplant has remained the gold standard therapy with good long-term outcome for patients with advanced heart failure in HK. However, the number of patients who could benefit from heart transplant remained limited by the number of organ donor available with on average about 12 successful heart transplants performed per year in the setting of 7.5 million population in the past 10 years and the mortality on heart transplant waiting list remained high in the past at about $20 \%$ per year on waiting list which was similar to the previously published waiting list mortality world-wide $(5,6,16)$.

Those who decompensated on waiting list requiring inotropic and/or short term mechanical circulatory support were at particularly high risk with expected mortality of more than $50 \%$ per year (17). The first landmark study REMATCH trial was published in 2001 which demonstrated superior 1-year survival with the use of pulsatile LVAD compared to optimal medical therapy ( $52 \%$ vs. $25 \%$, $\mathrm{P}=0.002$ ) (8) and resulted in Food and Drug Administration (FDA) approval for its use as DT in 2003. The development of a smaller continuous axial-flow LVAD resulted in more widespread use of LVAD for advanced heart failure after the publication of the HeartMate II BTT trial in 2007 which demonstrated 6-month and 1-year survivals of $75 \%$ and $68 \%$ (9) and led to FDA approval for its use as BTT in 2008 (7). A subsequent study demonstrated further 
Table 3 Time-dependent univariate and multivariate analysis for predictors of mortality on heart transplant waiting list before and after multiple imputation

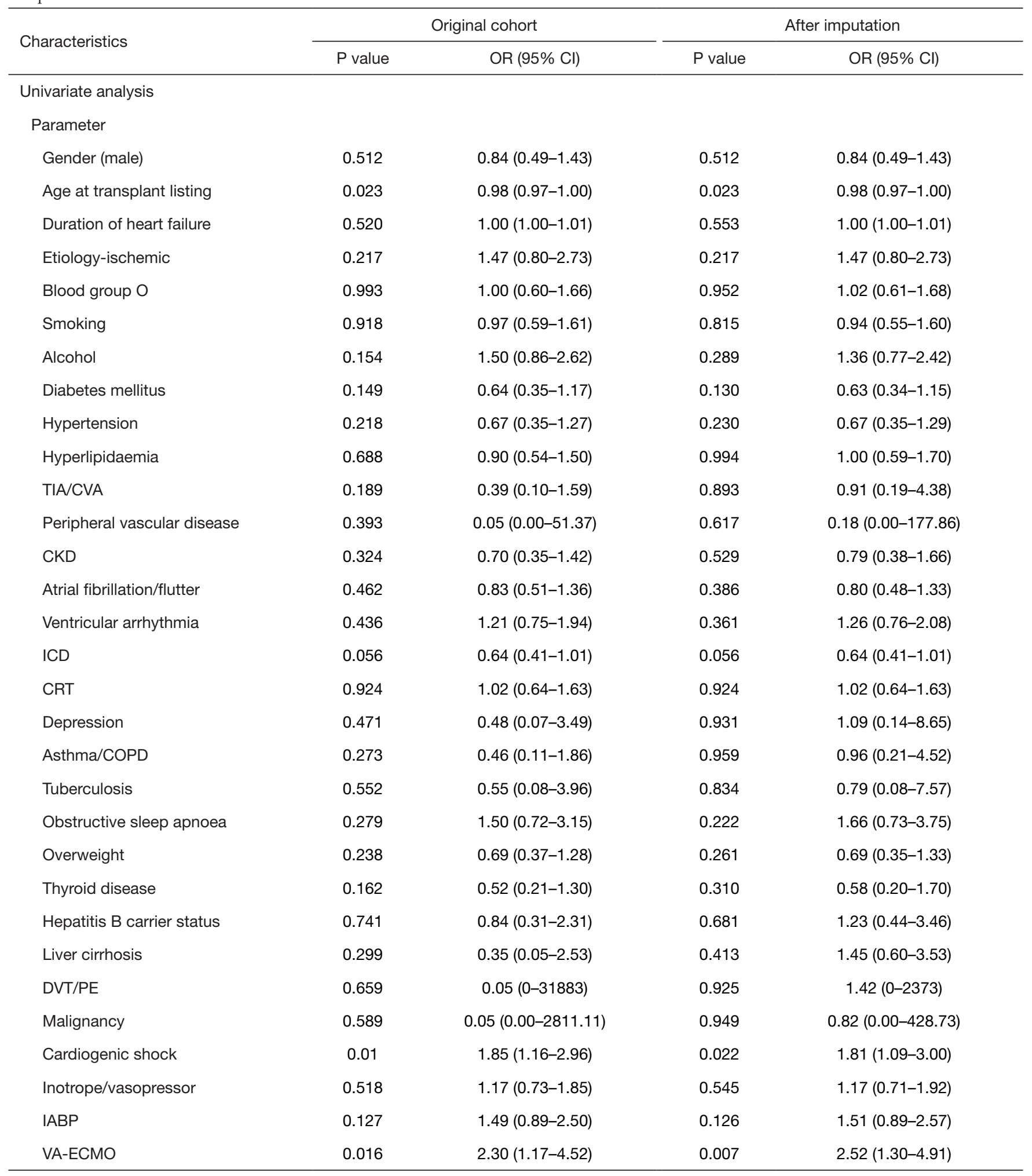

Table 3 (contnued) 
Table 3 (contnued)

\begin{tabular}{|c|c|c|c|c|}
\hline Characteristics & \multicolumn{2}{|c|}{ Original cohort } & \multicolumn{2}{|c|}{ After imputation } \\
\hline Impella & 0.014 & $4.32(1.35-13.81)$ & 0.014 & $4.32(1.35-13.81)$ \\
\hline Invasive MV & $<0.001$ & 4.09 (2.18-7.69) & $<0.001$ & $4.30(2.37-7.82)$ \\
\hline Temporary RRT & $<0.001$ & $4.30(1.96-9.46)$ & $<0.001$ & $4.45(2.15-9.22)$ \\
\hline LVEF & 0.930 & $0.98(0.69-1.40)$ & 0.881 & $0.97(0.67-1.42)$ \\
\hline Cardiac output & 0.659 & $1.14(0.63-2.05)$ & 0.286 & $1.37(0.75-2.49)$ \\
\hline Cardiac index & 0.496 & $1.01(0.98-1.05)$ & 0.590 & $1.01(0.97-1.05)$ \\
\hline PCWP & 0.555 & $0.98(0.93-1.04)$ & 0.710 & $1.01(0.95-1.07)$ \\
\hline $\mathrm{VO}_{2} \max$ & 0.296 & $1.06(0.95-1.17)$ & 0.331 & $1.04(0.96-1.13)$ \\
\hline Time to LVAD & 0.016 & $0.50(0.29-0.88)$ & 0.016 & $0.50(0.29-0.88)$ \\
\hline \multicolumn{5}{|l|}{ Multivariate analysis } \\
\hline \multicolumn{5}{|l|}{ Variables } \\
\hline Time to LVAD & 0.003 & $0.28(0.12-0.65)$ & $<0.001$ & $0.21(0.10-0.44)$ \\
\hline Age at transplant listing & 0.216 & $0.99(0.96-1.01)$ & 0.288 & $0.99(0.97-1.01)$ \\
\hline ICD & 0.224 & $1.59(0.75-3.35)$ & 0.889 & $0.96(0.56-1.65)$ \\
\hline Cardiogenic shock & $<0.001$ & $4.58(2.10-10.00)$ & 0.002 & $2.85(1.46-5.55)$ \\
\hline
\end{tabular}

Overweight, body mass index $>25 \mathrm{~kg} / \mathrm{m}^{2}$; Impella, intravascular microaxial LVAD; $\mathrm{VO}_{2}$ max, peak oxygen consumption on cardiopulmonary exercise test; Time to LVAD, time from heart transplant listing to LVAD support. OR, odds ratio; CI, confidence interval; TIA, transient ischemic attack; CVA, cerebral vascular event; ICD, implantable cardioverter defibrillator; CRT, cardiac resynchronization therapy; CKD, chronic kidney disease with estimated glomerular filtration rate less than $60 \mathrm{~mL} / \mathrm{min} / 1.73 \mathrm{~m}^{2}$; COPD, chronic obstructive pulmonary disease; DVT, deep vein thrombosis; PE, pulmonary Embolism; IABP, intra-aortic balloon pump; VA-ECMO, veno-arterial extra-corporeal membrane oxygenation; MV, mechanical ventilation; RRT, renal replacement therapy; LVEDD, left ventricular end-diastolic diameter; LVEF, left ventricular ejection fraction; PCWP, pulmonary capillary wedge pressure; RAP, right atrial pressure; PVR, pulmonary vascular resistance; LVAD, left ventricular assist device.

improved 18 -month survival of $72 \%$ as BTT with the accumulation of clinical experience (10). The latest generation LVADs are small centrifugal-flow intrapericardial LVADs which were shown to be non-inferior or even superior in clinical outcomes when compared to axial flow $\operatorname{LVAD}(11,12)$.

The first LVAD implantation in HK was performed in August 2010 and for the present cohort 110 patients were supported by LVAD as BTT by the end of study period. Overall survival rates of LVAD as BTT in the 
A

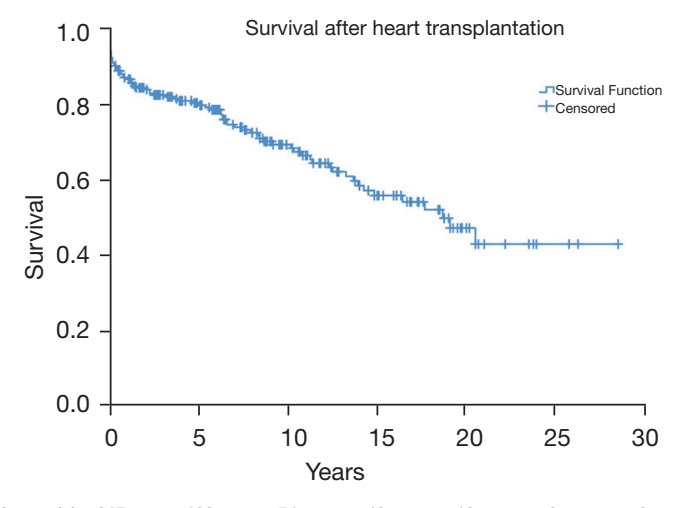

B
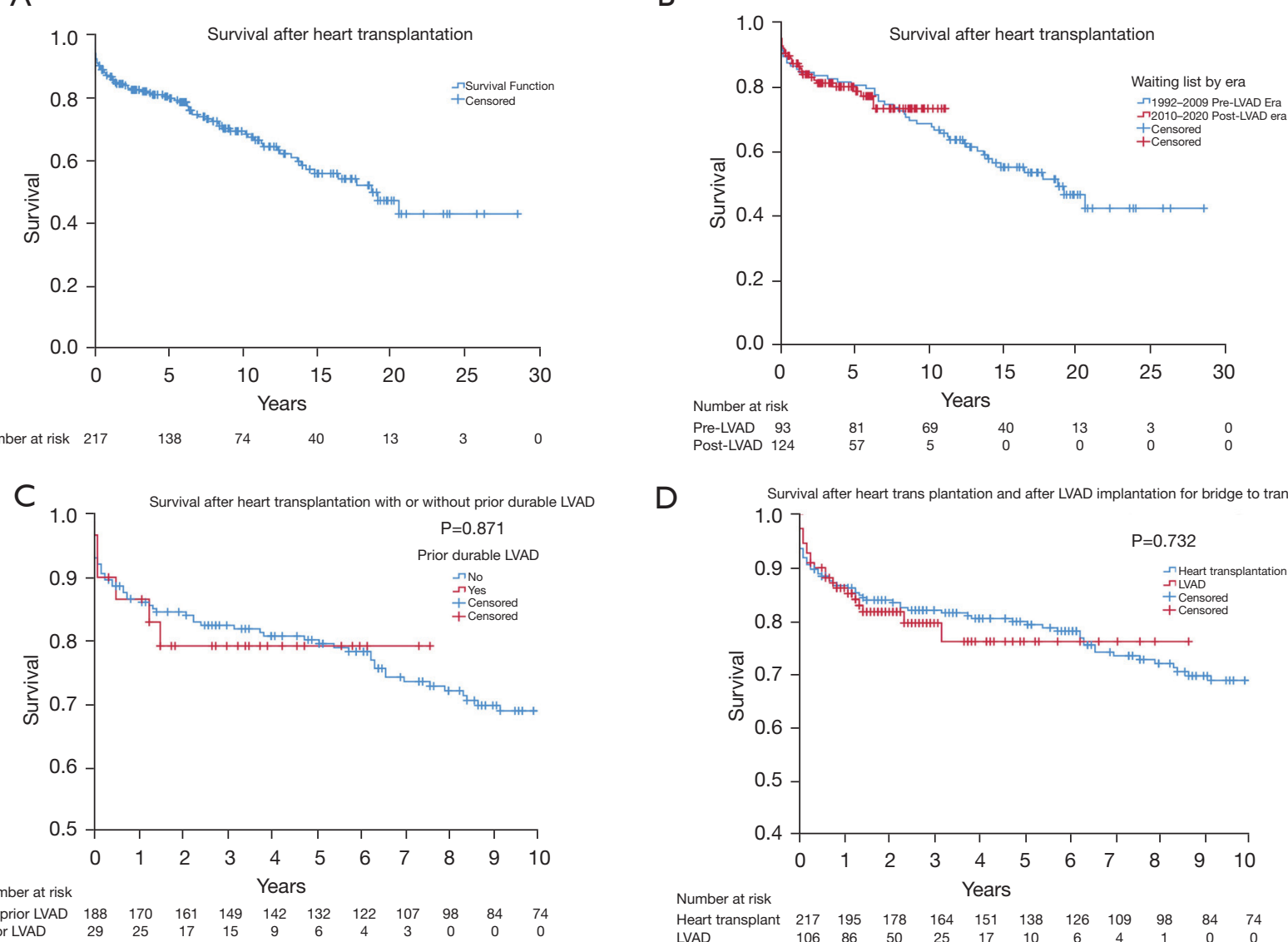

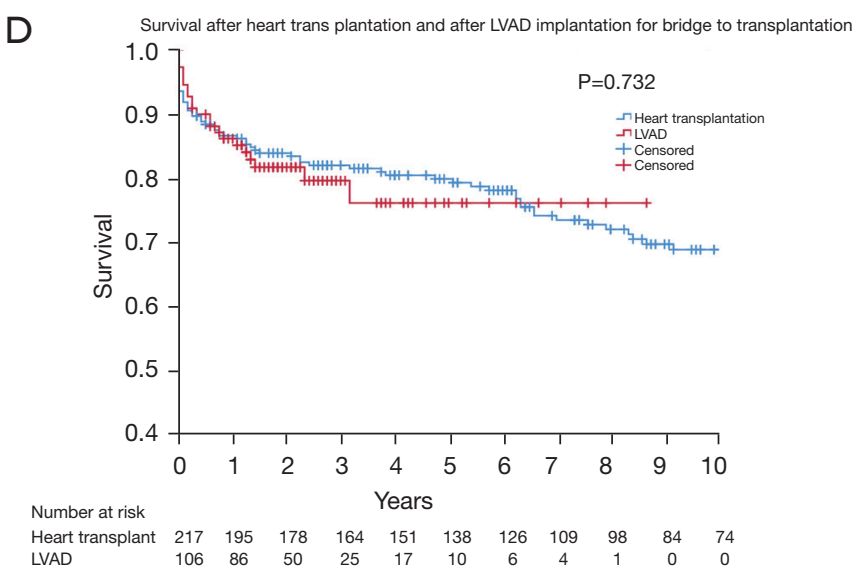

Figure 4 Showed the overall survival after HTx in HK, comparison of post-heart transplant survival in different eras and with or without prior LVAD support, as well as the comparison of survival after LVAD as BTT and survival after HTx. (A) Showed the long-term survival of heart transplant recipients in HK; (B) showed no significant difference in long-term post-heart transplant survival for patients listed in the pre-LVAD era 1992-2009 and post-LVAD era 2010-2020; (C) showed no significant difference in long-term post-heart transplant survival between recipients with and without prior durable LVAD as bridge to HTx; and (D) showed no significant difference between survival after LVAD as BTT and survival after HTx. LVAD, left ventricular assist device; HTx, heart transplantation; HK, Hong Kong; BTT, bridge to transplantation.

present cohort were $86.1 \%, 81.7 \%$ and $76.1 \%$ at 1 -, 2 and 4-year respectively which were comparable to the benchmark survival rates of $81 \%, 70 \%$ and $49 \%$ at 1-, 2 and 4-year respectively in the INTERMACS registry (18). Currently, only LVAD implantations for BTT or candidacy were eligible for central reimbursement in HK. The overall post heart transplant survival rates were $86.6 \%$ and $68.8 \%$ at 1 - and 10 -year respectively with median survival of 18.5 years (Figure $4 A$ ) in HK which was at least comparable if not superior to the survival rates of $84.0 \%$ and $56.8 \%$ at 1 - and 10-year as well as median survival of 11.9 years reported by the International Society of Heart and Lung
Transplantation (ISHLT) registry (4).

In the present study, several significant impacts on heart transplant service were demonstrated after the implementation of LVAD. First, the survival was significantly improved in the post-LVAD era because of the favorable long term LVAD survival which was demonstrated to be comparable to local HTx survival in this study. This observation was further supported by the time-dependent multivariate analysis which showed that LVAD support was independently associated with significant lower HTx waiting list mortality [OR: 0.21 (CI: $0.10-0.44), \mathrm{P}<0.001$ ]. Second, there was an increased number of patients on 
the waiting list in the post LVAD era. Two main reasons contributed to this. On one hand, more sick patients who would otherwise not be suitable for HTx were supported by LVAD and eventually became eligible for transplant listing. On the other hand, the mortality on the waiting list, especially those supported on LVAD, significantly decreased. Both factors contributed to the increase in prevalence of patients on the heart transplant waiting list. Third, the waiting time on the transplant waiting list was significantly increased especially for those who were on LVAD support. This observation was consistent with the recent major change in heart transplant allocation system in the United States with patients supported on durable LVAD being assigned to a lower priority on waiting list (19). As the outcome on LVAD support continued to improve and the number of patients on waiting list continued to increase, the increase in waiting time is not unexpected. Last, there was no change in post-transplant survival in the post LVAD era and when comparing post-transplant survival with prior LVAD support to those without prior LVAD support. This highlighted the post-transplant outcome was not compromised by the implementation of LVAD service.

This study has several strengths. First, as there is only one single institute organizing all the heart transplant and LVAD services in HK, this study clearly demonstrated the impact of LVAD service on HTx in the whole 7.5 million population. Second, the follow-up period was long and the LVAD survival up to about 8 years was demonstrated to be nearly equivalent to that of HTx. Third, this study represented a real world setting and even patients with cardiogenic shock required high level of mechanical circulatory support including VA-ECMO and Impella presenting INTERMACS I profile were included for survival analysis and these factors were also included in multivariate analysis; thus, selection bias would be less of a concern. Overall, our study is unique in demonstrating in an Asian city with good HTx outcome comparable to ISHLT results, patients supported with LVAD as BTT in a realworld setting has comparable long-term survival up to about 8 years to those patients received HTx $(76.1 \%$ vs. $72 \%$ at 8 years respectively). However, there are still some potential limitations of this study. First, due to the retrospective nature of the study, there were certain missing data upon data retrieval of patient characteristics. However, the proportion of missing data was not excessive at $6.6 \%$ and a multiple imputation strategy was employed to minimize the effect of missing data on final analysis. Second, this study only represented data in a city with predominantly Asian population and limited its generalizability. Third, there were significant changes in anti-heart failure medication therapy from 1992 to 2020 which might have an impact on waiting list survival. However, medication data was not available in the present cohort for multivariate analysis. Fourth, due to retrospective nature, the cause of death, especially death related to cardiovascular cause, death related to heart failure and death due to arrhythmia, cannot be further analyzed due to lack of data. Last, the number of patients included was relatively small compared to international registries and thus further large-scale studies are needed to confirm the findings of the present study.

\section{Conclusions}

Heart transplant waiting list survival improved in the postLVAD era driven by the use of LVAD support. The longterm survival of patients receiving LVAD as BTT was comparable to survival of heart transplant recipients up to about 8 years. Thus, given the scarce organ availability, it might be reasonable to triage patients who are stable on LVAD therapy to a lower priority on transplant waiting list or even as semi-DT.

\section{Acknowledgments}

Funding: None.

\section{Footnote}

Reporting Checklist: The authors have completed the STROBE reporting checklist. Available at https://dx.doi. org/10.21037/jtd-21-298

Data Sharing Statement: Available at https://dx.doi. org/10.21037/jtd-21-298

Peer Review File: Available at https://dx.doi.org/10.21037/ jtd-21-298

Conflicts of Interest: All authors have completed the ICMJE uniform disclosure form (available at https://dx.doi. org/10.21037/jtd-21-298). The authors have no conflicts of interest to declare.

Ethical Statement: The authors are accountable for all aspects of the work in ensuring that questions related to the accuracy or integrity of any part of the work are 
appropriately investigated and resolved. The study was conducted in accordance with the Declaration of Helsinki (as revised in 2013). The study was approved by the institutional ethics review board (IRB/REC No. UW 20388 ) and individual consent for this retrospective analysis was waived.

Open Access Statement: This is an Open Access article distributed in accordance with the Creative Commons Attribution-NonCommercial-NoDerivs 4.0 International License (CC BY-NC-ND 4.0), which permits the noncommercial replication and distribution of the article with the strict proviso that no changes or edits are made and the original work is properly cited (including links to both the formal publication through the relevant DOI and the license). See: https://creativecommons.org/licenses/by-nc-nd/4.0/.

\section{References}

1. Ammar KA, Jacobsen SJ, Mahoney DW, et al. Prevalence and prognostic significance of heart failure stages: application of the American College of Cardiology/American Heart Association heart failure staging criteria in the community. Circulation 2007;115:1563-70.

2. Yancy CW, Jessup M, Bozkurt B, et al. 2013 ACCF/AHA guideline for the management of heart failure: a report of the American College of Cardiology Foundation/American Heart Association Task Force on Practice Guidelines. J Am Coll Cardiol 2013;62:e147-239.

3. Ponikowski P, Voors AA, Anker SD, et al. 2016 ESC Guidelines for the diagnosis and treatment of acute and chronic heart failure: The Task Force for the diagnosis and treatment of acute and chronic heart failure of the European Society of Cardiology (ESC)Developed with the special contribution of the Heart Failure Association (HFA) of the ESC. Eur Heart J 2016;37:2129-200.

4. Khush KK, Cherikh WS, Chambers DC, et al. The International Thoracic Organ Transplant Registry of the International Society for Heart and Lung Transplantation: Thirty-sixth adult heart transplantation report - 2019; focus theme: Donor and recipient size match. J Heart Lung Transplant 2019;38:1056-66.

5. Jasseron C, Legeai C, Jacquelinet C, et al. Prediction of Waitlist Mortality in Adult Heart Transplant Candidates: The Candidate Risk Score. Transplantation 2017;101:2175-82.

6. Blackstone EH, Rajeswaran J, Cruz VB, et al. Continuously Updated Estimation of Heart Transplant Waitlist Mortality. J Am Coll Cardiol 2018;72:650-9.
7. Stewart GC, Givertz MM. Mechanical circulatory support for advanced heart failure: patients and technology in evolution. Circulation 2012;125:1304-15.

8. Rose EA, Gelijns AC, Moskowitz AJ, et al. Long-term use of a left ventricular assist device for end-stage heart failure. $\mathrm{N}$ Engl J Med 2001;345:1435-43.

9. Miller LW, Pagani FD, Russell SD, et al. Use of a continuousflow device in patients awaiting heart transplantation. $\mathrm{N}$ Engl J Med 2007;357:885-96.

10. Pagani FD, Miller LW, Russell SD, et al. Extended mechanical circulatory support with a continuous-flow rotary left ventricular assist device. J Am Coll Cardiol 2009;54:312-21.

11. Aaronson KD, Slaughter MS, Miller LW, et al. Use of an intrapericardial, continuous-flow, centrifugal pump in patients awaiting heart transplantation. Circulation 2012;125:3191-200.

12. Mehra MR, Uriel N, Naka Y, et al. A Fully Magnetically Levitated Left Ventricular Assist Device - Final Report. N Engl J Med 2019;380:1618-27.

13. Kirklin JK, Naftel DC, Pagani FD, et al. Seventh INTERMACS annual report: 15,000 patients and counting. J Heart Lung Transplant 2015;34:1495-504.

14. Teuteberg JJ, Cleveland JC Jr, Cowger J, et al. The Society of Thoracic Surgeons Intermacs 2019 Annual Report: The Changing Landscape of Devices and Indications. Ann Thorac Surg 2020;109:649-60.

15. WHO Expert Consultation. Appropriate body-mass index for Asian populations and its implications for policy and intervention strategies. Lancet 2004;363:157-63.

16. Weiss J, Beyeler F, Immer FF, et al. Heart allocation and transplantation in Switzerland since the introduction of the Swiss Organ Allocation System (SOAS). Swiss Med Wkly 2014;144:w14057.

17. Hashim T, Sanam K, Revilla-Martinez M, et al. Clinical Characteristics and Outcomes of Intravenous Inotropic Therapy in Advanced Heart Failure. Circ Heart Fail 2015;8:880-6.

18. Kirklin JK, Pagani FD, Kormos RL, et al. Eighth annual INTERMACS report: Special focus on framing the impact of adverse events. J Heart Lung Transplant 2017;36:1080-6.

19. Cogswell R, John R, Estep JD, et al. An early investigation of outcomes with the new 2018 donor heart allocation system in the United States. J Heart Lung Transplant 2020;39:1-4.

Cite this article as: Wong KL, Ho KLC, Lee OJ, Lun KS, Bhatia I, Tam WYE, Fan YYK, Au WKT. Emerging roles of left ventricular assist device therapy as bridge to transplant in an Asian city with scarce heart transplant donor. J Thorac Dis 2021;13(10):5717-5730. doi: 10.21037/jtd-21-298 
Table S1 Characteristics of the study cohort before and after multiple imputation

\begin{tabular}{|c|c|c|c|c|c|}
\hline \multirow{2}{*}{ Characteristics } & \multicolumn{3}{|c|}{ Original cohort } & \multicolumn{2}{|c|}{ After imputation $(n=478)$} \\
\hline & $n$ & Mean/count & $\mathrm{SD} /$ percentage & Mean/count & $\mathrm{SD} /$ percentage \\
\hline Gender (male) & 478 & 353 & $73.9 \%$ & 353 & $73.9 \%$ \\
\hline Age at transplant listing & 478 & 43.9 & 14.3 & 43.9 & 14.3 \\
\hline Duration of heart failure (months) & 471 & 53.5 & 64.3 & 53.8 & 64.3 \\
\hline Etiology-ischemic & 478 & 104 & $21.8 \%$ & 104 & $21.8 \%$ \\
\hline Blood group $\mathrm{O}$ & 448 & 177 & $39.5 \%$ & 189.2 & $39.6 \%$ \\
\hline Smoking & 453 & 181 & $40.0 \%$ & 192.2 & $40.2 \%$ \\
\hline Alcohol & 446 & 87 & $19.5 \%$ & 93.8 & $19.6 \%$ \\
\hline Diabetes mellitus & 471 & 115 & $24.4 \%$ & 116.6 & $24.4 \%$ \\
\hline Hypertension & 471 & 86 & $18.3 \%$ & 87.6 & $18.3 \%$ \\
\hline Hyperlipidaemia & 470 & 138 & $29.4 \%$ & 143.8 & $30.1 \%$ \\
\hline TIA/CVA & 470 & 34 & $7.2 \%$ & 40.4 & $8.5 \%$ \\
\hline Peripheral vascular disease & 470 & 8 & $1.7 \%$ & 10.6 & $2.2 \%$ \\
\hline CKD & 453 & 88 & $19.4 \%$ & 94.6 & $19.8 \%$ \\
\hline Atrial fibrillation/flutter & 464 & 179 & $38.6 \%$ & 184 & $38.5 \%$ \\
\hline Ventricular arrhythmia & 470 & 150 & $31.9 \%$ & 155 & $32.4 \%$ \\
\hline ICD & 478 & 206 & $43.1 \%$ & 206 & $43.1 \%$ \\
\hline CRT & 478 & 152 & $31.8 \%$ & 152 & $31.8 \%$ \\
\hline Depression & 470 & 10 & $2.1 \%$ & 15 & $3.1 \%$ \\
\hline Asthma/COPD & 469 & 23 & $4.9 \%$ & 28.8 & $6.0 \%$ \\
\hline Tuberculosis & 470 & 12 & $2.6 \%$ & 13.8 & $2.9 \%$ \\
\hline Obstructive sleep apnoea & 470 & 25 & $5.3 \%$ & 28.8 & $6.0 \%$ \\
\hline Overweight & 468 & 82 & $17.5 \%$ & 84.2 & $17.6 \%$ \\
\hline Thyroid disease & 470 & 49 & $10.4 \%$ & 51.4 & $10.8 \%$ \\
\hline Hepatitis B carrier status & 468 & 29 & $6.2 \%$ & 33.4 & $7.0 \%$ \\
\hline Liver cirrhosis & 469 & 13 & $2.8 \%$ & 19.2 & $4.0 \%$ \\
\hline DVT/PE & 470 & 3 & $0.6 \%$ & 7.4 & $1.6 \%$ \\
\hline Malignancy & 470 & 8 & $1.7 \%$ & 11.4 & $2.4 \%$ \\
\hline Cardiogenic shock & 470 & 143 & $30.4 \%$ & 146.6 & $30.7 \%$ \\
\hline Inotrope/vasopressor & 470 & 190 & $40.4 \%$ & 197.8 & $41.4 \%$ \\
\hline IABP & 470 & 100 & $21.3 \%$ & 103.6 & $21.7 \%$ \\
\hline VA-ECMO & 470 & 44 & $9.4 \%$ & 48.8 & $10.2 \%$ \\
\hline Impella & 478 & 6 & $1.3 \%$ & 6 & $1.3 \%$ \\
\hline Invasive MV & 470 & 38 & $8.1 \%$ & 42.4 & $8.9 \%$ \\
\hline Temporary RRT & 470 & 22 & $4.7 \%$ & 26.6 & $5.6 \%$ \\
\hline LVEDD (cm) & 360 & 6.6 & 1.4 & 6.5 & 1.4 \\
\hline LVEF (\%) & 384 & 22.8 & 12.7 & 23.6 & 12.9 \\
\hline Cardiac output (L/min) & 345 & 3.1 & 1.0 & 3.0 & 1.0 \\
\hline Cardiac index $\left(\mathrm{L} / \mathrm{min} / \mathrm{m}^{2}\right)$ & 342 & 1.9 & 0.6 & 1.9 & 0.6 \\
\hline PCWP (mmHg) & 335 & 21.3 & 9.5 & 21.4 & 9.7 \\
\hline $\mathrm{RAP}(\mathrm{mmHg})$ & 308 & 11.0 & 7.1 & 11.8 & 7.3 \\
\hline PVR (Wood's unit) & 339 & 3.7 & 3.5 & 3.9 & 3.4 \\
\hline $\mathrm{VO}_{2} \max (\mathrm{mL} / \mathrm{kg} / \mathrm{min})$ & 236 & 14.9 & 4.6 & 15.3 & 5.1 \\
\hline Duration on waiting list (months) & 478 & 13.4 & 17.0 & 13.4 & 17.0 \\
\hline Death on waiting list & 478 & 78 & $16.3 \%$ & 78 & $16.3 \%$ \\
\hline
\end{tabular}

Overweight, body mass index $>25 \mathrm{~kg} / \mathrm{m}^{2}$; Impella, intravascular microaxial LVAD; $\mathrm{VO}_{2}$ max, peak oxygen consumption on cardiopulmonary exercise test. SD, standard deviation; TIA, transient ischemic attack; CVA, cerebral vascular event; CKD, chronic kidney disease with estimated glomerular filtration rate less than $60 \mathrm{~mL} / \mathrm{min} / 1.73 \mathrm{~m}^{2}$; COPD, chronic obstructive pulmonary disease; DVT, deep vein thrombosis; PE, pulmonary embolism; IABP, intra-aortic balloon pump; VA-ECMO, veno-arterial extra-corporeal membrane oxygenation; MV, mechanical ventilation; RRT, renal replacement therapy; LVEDD, left ventricular end-diastolic diameter; LVEF, left ventricular ejection fraction; PCWP, pulmonary capillary wedge pressure; RAP, right atrial pressure; PVR, pulmonary vascular resistance. 